\title{
CORRELATES OF ENHANCING RETWEETS AMONG USERS: THE CASE OF NISSAN
}

\author{
CORRELACIONES DE LA AMPLIACIÓN DE RETWEETS ENTRE LOS USUARIOS: \\ EL CASO DE NISSAN
}

\author{
Eva Lahuerta-Otero ${ }^{\mathrm{a}}$ Rebeca Cordero-Gutiérrez ${ }^{\mathrm{b}}$
}

Classification: Empirical paper - research

Received: June 8, 2020 / Revised: September 11, 2020 / Accepted: November 7, 2020

\begin{abstract}
The purpose of this paper is to determine which elements of Twitter stimulate the dissemination of messages in the microblogging community. We collected a database of 1,112 Spanish-speaking users for this study who had mentioned the keyword "Nissan" in their tweets, and performed a multiple regression analysis. We have found that certain characteristics of tweets (longer tweets that express feelings through mentions and lexical diversity) obtain higher dissemination rates compared to those that do not. Hashtags and links seem to distract users from processing the information and do not act as heuristic cues. Users want to find heuristic cues that help them process information easily in social media. However, the use of links or hashtags in tweets does not help with dissemination, as these elements distract users and decrease the limited writing space available. This paper offers insightful options for brands, marketers and professionals on how to maximize the impact of social media at no additional cost.
\end{abstract}

Keywords: Marketing communication, social media, Twitter, tweet elements, diffusion, Nissan.

\section{Resumen}

El propósito de este artículo es determinar qué elementos de Twitter estimulan la difusión de mensajes en la comunidad de microbloggers. Para este estudio se recopiló una base de datos de 1112 usuarios de habla hispana que habían mencionado la palabra clave "Nissan" en sus tweets y se realizó un análisis de regresión múltiple. Hemos comprobado que ciertas características de los tweets (mensajes más largos que expresan sentimientos a través de las menciones y la diversidad léxica) obtienen mayores tasas de difusión en comparación con los que no lo hacen. Los hashtags y los enlaces parecen distraer a los usuarios del procesamiento de la información y no actúan como pistas heurísticas. Los usuarios quieren encontrar pistas heurísticas que les ayuden a procesar la información fácilmente en los medios sociales. Sin embargo, el uso de enlaces o hashtags en los tweets no ayuda a la difusión, ya que estos elementos distraen a los usuarios y disminuyen el limitado espacio de escritura disponible. Este estudio ofrece alternativas útiles para las marcas, los agentes de marketing y los profesionales de empresa sobre la forma de maximizar el impacto de los medios de comunicación social sin costo adicional.

Palabras clave: comunicación de marketing, medios sociales, Twitter, elementos de tweet, difusión, Nissan.

IME/Universidad de Salamanca, Business Administration, Salamanca, Spain. Email: eva.lahuerta@usal.es

b Pontifical University of Salamanca, Faculty of Computer Science / School of Languages and Education, Nebrija University, Salamanca/ Madrid, Spain. Email: rcorderogu@upsa.es 


\section{Introduction}

The world is going digital. The latest report from We are Social \& Hootsuite (2020) reveals that more than 4.5 billion people currently use the Internet, while social media users have surpassed the 3.8 billion mark, representing a global penetration of $49 \%$. Compared to 2019 , active users of social media grew by $9.2 \%$ (321 million). This means, for example, that 190 million users joined social networks in Asia and the Pacific alone in 2019 (a growth rate of 9.8 percent) or 38 million new users in the Americas. Therefore, social media is part of our lives today. We use virtual communities to communicate, inform and interact with family and friends, but also with brands.

Twitter is one of the most powerful and well-known microblogging sites worldwide. It currently has 330 million monthly users, most of whom are from the United States (Statista, 2020a). Since this platform is a simple and effective social communication system, the world sends 8,980 tweets every second, which means more than $776,044,800$ tweets daily (Internet Live Stats, 2020). Therefore, this virtual community generates and disseminates a large amount of information with a simple mouse click, promotes customer interaction and content generation (Steyn et al., 2011) and becomes an excellent means of keeping informed about daily news (Hoeber et al., 2016).

Twitter is also a valuable loudspeaker for brands, celebrities and organizations, and the use of microblogging social tools among Latin American countries is also very widespread. In February 2020, Brazil was the Latin American country with the most Twitter users: approximately 12.15 million. It was followed by Mexico with 9.45 million and Argentina with 4.96 million users. Overall, social networks remain one of the main online activities in Latin America (Statista, 2020b). In addition, Latin American presidents are the biggest users of social media by politicians, especially on Twitter (Direct Marketing, 2020).

Consumers are also responding to this new form of interaction, as they are more likely to remember the ads seen on Twitter and take action later. For example, $42 \%$ of users seek additional information about a product or brand and are more likely to share the results with their friends. In addition, $78 \%$ of customers are more likely to post or share a post about a brand on social media and, more importantly, $120 \%$ are willing to contact brands directly. In turn, an active presence on Twitter makes brands feel more human and trustworthy (Ward, 2019).

According to Syrkiewitcz-Switala et al., (2016), information sources should be adapted to the current version 2.0 live, because users want to receive information in a comfortable, adapted and practical way. Therefore, it is essential that brands understand which elements of a message can improve retweeting, since it is a measure of diffusion and propagation of a tweet. There are two ways in which users can influence others. First, someone must have enough influence and persuasion on Twitter to generate attention when writing, and second, users must transmit that message to others, helping to create electronic word of mouth (e-WOM) (Oh \& Nguyen, 2010).

When a user resends content, it helps the brand to spread the information for free, so identifying which elements of the message (hashtags, mentions, links, feeling...) favour the spread can help brands and companies to write and spread the messages more efficiently (Lahuerta-Otero \& Cordero-Gutiérrez, 2016). The purpose of this paper is simple: given the lack of literature on empirical research in this field (Ikeda et al., 2013) we intend to identify the characteristics of tweets that facilitate re-tweeting using a set of data from the automotive industry.

The paper is structured as follows: First, we describe the previous literature to determine the materials and methods used in the research. Next, we describe the results of our empirical research conducted on a database of tweets published by 1,112 users and their discussion and implications for the industry. Finally, we include a conclusion section to highlight the most relevant findings of our research.

\section{Background and Prior Literature}

With millions of tweets being sent every day, users face difficulties in processing information quickly and efficiently. There are several elements in a message (integrity, relevance, security, timeliness...) that can improve its quality, making it more relevant to users who want to know about news, brands or companies (Alexander \& Tate, 1999; Parker et al., 2006; Strong et al., 1997).

Microblogging social sites create an important source of electronic information (Erkan \& Evans, 2016; Jansen et al., 2009), as information can be transmitted quickly and effectively. Unlike other social networks, Twitter users do not need to follow each other to read their publications. Therefore, every time a user publishes a new message, it is made public and immediately accessible to all members of the social network. This means that users and brands can immediately check users' reactions, attitudes and opinions about a message, getting automatic and instant feedback (Sankaranarayanan et al., 2009).

The most influential Twitter users will be able to involve others in the joint creation of value, since the rest of the community's users perceive their messages as reliable and trustworthy (Bongwon et al., 2010). This does not necessarily mean that influential users must have 
large audiences, as some authors indicate that the spread of tweets indicates relevance, rather than the number of followers (Cha et al., 2010; Messias et al., 2013). Therefore, it is necessary to study which characteristics of the message facilitate the processing of information for users and enable its dissemination, since e-WOM can influence brand image, perceptions and purchase decisions (Reynolds, 2006; Urban, 2005).

The most recent research (Lahuerta-Otero et al., 2018; Liu e tal., 2012; Zhang et al, 2014; Zhang \& Watts, 2008;) uses the heuristic-systemic model of information processing (Chaiken, 1980) to analyse why some messages are more widespread than others and spread more quickly through social media. The model states that there are two ways to process information. First, there is systematic information processing in which users need to have sufficient time and resources to process a message based on its content (Flanagin \& Metzger, 2007; Metzger et al., 2010; Taraborelli, 2008).

Since users do not have time to process millions of messages every day, they use a set of alternative strategies and heuristics to process the information more easily. Using contextual elements (such as message characteristics) they can evaluate the quality of the information without making a detailed analysis of the information contained in a tweet (Chaiken, 1987; Fogg, 2003; Lahuerta-Otero et al., 2018; Lang, 2000). When heuristic keys are used, readers give credibility to the messages based on their characteristics, rather than on the content itself.

\section{Tweets' Characteristics and Message Diffusion}

Members of the virtual communities use both heuristic and systematic cues when processing information, so we will describe which characteristics of tweet messages can favour its propagation in the form of retweets, in line with previous research (Hao et al., 2016; Zhang et al., 2014; Zhang \& Peng, 2015; Zhang \& Watts, 2008).

\section{Tweet Length}

Twitter is a microblogging platform with a 280 -character restriction. Therefore, users must synthesize the messages to express all the information efficiently. Sometimes, users have difficulty in expressing large opinions or messages through a short message, so they use external links. Several researches have tried to determine the ideal length of a message on Twitter (Bennet, 2014; Lahuerta-Otero et al., 2018; Lee, 2015; Zhang \& Peng, 2015 ,). In general, most of the authors conclude that the longer the tweet, the better its dissemination possibilities. Therefore, we propose the following:
H1: The longer the tweet, the more retweets.

\section{Sentiment}

Many users find it difficult to express a full set of emotions (irony, joy, anger, disappointment...) in a short Twitter message. However, marketers and researchers are aware of the importance of emotions when writing, given that it creates greater brand involvement and facilitates dissemination on microblogging platforms (Hansen et al., 2011; Lahuerta-Otero \& CorderoGutiérrez, 2016; Lahuerta-Otero et al.,2018, Zhang \& Peng, 2015). Users and brands need to ensure that their message attracts and engages their audience, so they try to write tweets that motivate their audiences. As a result, they tend to express different feelings when writing (Boyd et al., 2010; Hutchison \& Kumara, 2013; Java et al., 2007) in order to capture the attention of the users and provoke action (usually through a retweet). We propose the following hypothesis accordingly:

$\mathrm{H} 2$ : Users expressing sentiments regarding tweets will get more retweets.

\section{Links}

Twitter is a microblogging platform with a 140 -character restriction that was updated to a maximum of 280 characters in 2017. Although links will not be counted for the 280-character maximum when typing in the future (Twitter, 2016), users have to leave the platform when clicking on an external link. This means an additional effort to process the information, so the heuristic cue may become distracting (Liu et al., 2012). Although there is some controversy about the use of links to complement the information in tweets, some empirical research (Lee, 2015; Ross, 2014) considers that the use of links does not favour the dissemination of tweets. Therefore, we propose the following hypothesis:

H3: The greater the use of external links in a tweet, the less retweets.

\section{Mentions and Hashtags}

There are several ways to provide interactivity on Twitter. First, when users want to direct others, they can add the "@”" symbol before their username, which means a mention. By doing this, the user is directly notified that someone has mentioned them in a message, so they can perform an action (such as liking, replying or commenting). Several empirical studies (Enge, 2014; Kietzmann 
et al., 2011; Lahuerta-Otero \& Cordero-Gutiérrez, 2016; Lahuerta-Otero et al.,2018; Zhang \& Peng, 2015) confirm that mentions help spread the messages on microblogging platforms, because users tend to show others that they support by spreading the message to their contacts.

On the other hand, we can also consider that hashtags can be a way to improve the interactivity and dissemination of messages. By adding the "\#” symbol before a tweet, users convert the words into keywords that allow categorization. Therefore, users can group messages into topics in order to process the information more efficiently (a heuristic cue). The most talked about topics at the moment are called trending topics and allow Twitter users to process information easily (Gul et al., 2016; Scott, 2015) and brands can increase the public's attention (Wang et al., 2016). Consequently, and according to previous research (Enge, 2014; Kietzmann et al., 2011; Lahuerta-Otero \& Cordero-Gutiérrez, 2016; LahuertaOtero et al.,2018) the use of hashtags improves the diffusion of tweets. Therefore, and in line with the above, we propose the following hypotheses:

H4: The greater the use of mentions in a tweet, the more retweets.

H5: The greater the use of hashtags in a tweet, the more retweets.

\section{Influence}

We can measure the influence of users on social media using different indicators. One of the best-known tools is the Klout score, which uses data from various social user profiles to rank them from 0 to 100 (Klout, 2016). However, the use of Klout as an influence score does not distinguish the individual power of a user in a single network, given that it is a combination of indicators. Consequently, only $3 \%$ of marketers believe it is a valuable tool for measuring social influence (Augure, 2014). To overcome these limitations, the University of Salamanca, through the BISITE research group and the PIAR project, has developed an algorithm that is capable of creating an alternative score that is based solely on the influence of Twitter, allowing us to provide more information on how the influence impacts dissemination. When users retweet a message, they think the content is useful for their followers, given its greater reach. Therefore, retweeting involves electronic word of mouth (e-WOM). The more influential the user is, the more credibility the tweet has with the audience, since they are considered experts in the industry and a source of valuable information (Mavrck, 2014). Recent research shows that the most influential users (who use the Klout score) get an average of 193 retweets, compared to users with a Klout score between 0 and 29, who only get 6 retweets on average (Infographic list, 2012). Accordingly, we propose:

H6: The greater the influence of a user on Twitter, the more retweets.

\section{Lexical Diversity}

Twitter is a horizontal social network, which means that users talk about many different topics. Depending on the popularity of the topic, they become more relevant as users participate in its dissemination. Internet users cannot process all the tweets on each of the topics, so they become selective and pay more attention to the tweets containing the topics they are interested in (Weng et al., 2010). When users become experts in a field, they tend to write valuable content for their followers. Therefore, they will try to express themselves in a way that indicates their level of expertise, which means they use a more diverse vocabulary to be able to discuss the topic in depth. Russel (2013) states that Twitter users write more interesting topics for their audience, which favours dissemination. Consequently, we formulate the following hypothesis:

H7: Users with high lexical diversity get more retweets.

\section{Following}

Twitter is a virtual community where users normally follow each other. First, because they might be interested in following the most influential users in order to participate in co-creation and e-WOM. This is why some authors think that influence has more to do with spreading messages and influencing, rather than having a large number of followers (Cha et al., 2010; Messias et al., 2013). Since it is easy and simple to follow others on Twitter, some users do so out of courtesy, so influence and spread increase when a large number of people have access to the messages (Chu \& Kim, 2011). Therefore, for e-WOM it is important that the user who publishes tweets follows a large number of people in the community (in addition to having many followers) to help spread the messages (Okazaki et al., 2014). Our hypothesis is as follows:

H8: Users following more people on Twitter get more retweets.

In order to empirically test all the hypotheses mentioned above, we propose the following regression equation: 


$$
\begin{aligned}
\operatorname{Ret}_{\mathrm{i}}= & \beta_{0}+\beta_{1} \mathrm{TL}_{\mathrm{i}}+\beta_{2} \mathrm{~S}_{\mathrm{i}}+\beta_{3} \mathrm{~L}_{\mathrm{i}}+\beta_{4} \mathrm{M}_{\mathrm{i}}+\beta_{5} H_{\mathrm{i}}+ \\
& \beta_{6} \mathrm{I}_{\mathrm{i}}+\beta_{7} L D_{\mathrm{i}}+\beta_{8} \mathrm{~F}_{\mathrm{i}}+\mathrm{e}_{\mathrm{i}}
\end{aligned}
$$

\section{Materials and Methods}

The data used in the present paper have been obtained from the microblogging social network, Twitter. We select this platform mainly for two reasons: 1 . because it is the most important in this type of social network, and 2. because its privacy features allow for the simple compilation of tweets generated by users, as well as data of their own activity. We collected data through a Twitter API that is integrated in a tool called PIAR developed by BISITE Research Group (University of Salamanca). This tool chronologically collects all the tweets, their structure, and information about the users that publish them (sentiment, mentions, retweets and information about influence and activity of the user, among others) associated with a previously fixed keyword.

For this study we have compiled a database of 1,112 Spanish-speaking users who have mentioned the keyword "Nissan" in their tweets between July 13 and 25, 2016. We chose this brand because of its importance in the automotive sector and also because it is a wellknown brand at an international level. In addition, Nissan's sales increased by more than $14 \%$ in South America in 2017, and total vehicle sales in the region were the highest since 2014. Nissan sold more than 200,000 vehicles in Latin America in 2017, the best results since it began operations in this market in 2014. Sales in Argentina grew by $71 \%$ with respect to 2016 , which means a $5 \%$ increase in market share. Sales in Brazil increased by $26 \%$, where Nissan represents $46 \%$ of the market, and it is the largest importer of vehicles in the Colombian market. Nissan is the fourth largest importer in terms of market share in Chile, where sales increased by $16 \%$, and it has a 5\% market share in Peru, where it has only recently begun operations (Nissan, 2018).

\section{Measurements}

The measures used in the study are described below:

- Diffusion of tweets (dependent variable): Retweets (Ret): reflects whether a user's tweet has been shared by other users or not.

Content of the tweets (independent variables):

- Tweet Length (TL): collects the average number of words that a user uses in their tweets.

- Sentiment (S): dichotomous variable that specifies if a tweet has neutral feeling or it reflects feelings (positive or negative). The measurement of sentiment is an automatic process in this case; i.e., a machine estimates the sentiment of a text that has been written by a person, detecting a positive or negative meaning that is more or less intense. For the purpose of this research, the sentiment model has been based on the one developed by Brooke et al. (2009). To this model, we have added phases to adapt it to the particularities of social networks (use of emoticons, abbreviations and spelling errors).

- Links (L): collects in a dichotomous variable if the tweet contains, or not, links in the text.

- Mentions (M): collects in a dichotomous variable if the tweet contains, or not, mentions of other users in the text.

- Hashtags $(\mathrm{H})$ : collects in a dichotomous variable whether the tweet contains, or not, hashtags in the text.

- Influence (I): it is a measure that reflects the influence of the user in the social network (similar to Klout Score). PIAR measures the influence in a ranking from 0 to 100 .

- This indicator is based on the users' followers in order to evaluate their popularity and influence on the social network (Carr \& Brock, 2013).

- Lexical Diversity (LD): captures the ratio between the unique words a user posts on a tweet divided by the total number of words he/she has written in the data collection period. Ranking from 0 to 1 , this metric becomes more relevant as the number of tweets published by a user increases.

- Followings (F): the variable captures the number of users an individual follows on Twitter.

\section{Results and Discussion}

For the empirical analysis of this research (see Table 1) we use IBM SPSS 23.0 to test data using a multiple regression model with the stepwise method.

The model proposed in the present study is statistically significant and reaches an adjusted $\mathrm{R}$ square of $26.6 \%$. If we take into account the hypotheses, not all of them have been validated in the work as only five out of the eight elements proposed in the literature review have been relevant in explaining the existence or retweets.

However, we can see that the H1 hypothesis is supported $(\beta=0.136, p<0.000)$, which means that tweets that have a larger number of words (and therefore a greater length) are more likely to be shared by a user. This fact coincides with the findings of the literature review since, 
as argued, longer tweets provide more information. If we are talking about a vehicle, a product of high involvement in which the customer makes great expenses, more information is valued positively by the user. Therefore, it is more likely that the message is spread through a retweet. The H2 hypothesis has also been supported, which postulated that tweets written with some feeling (positive or negative), that is, not neutral, had more retweets $(\beta=0.093, p<0.000)$. This is an expected result since in a product like the car, the user will be more willing to share those publications that are concerned with describing the aspects, experiences or opinions (positive or negative) about the product or the brand. This is consistent with Bae \& Lee's (2012) research that users respond favourably (retweeting) to positive tweets.

Hypotheses H3 and H5 have not been supported. Therefore, we suppose that users do not like that these elements can occupy the writing space of a tweet. In addition, in the case of links, the additional information that they could obtain implies that they have to leave the Twitter environment, which distracts users (Enge, 2014; Malhotra et al., 2012).

On the other hand, there is support for the H4 hypothesis. This hypothesis indicates that mentions are essential elements to increase the volume of retweets $(\beta=0.392$, $\mathrm{p}<0.000)$. When an individual is mentioned in a tweet by another user it is assumed that the content is relevant. Therefore, the possibilities of sharing that content are greater than in any other tweet where the recipient is not personalized.

In relation to the influence variable (H6), it has no relevance to explain the retweets on the Twitter platform. This fact may surprise us, but we must be aware that in a network of this type, it is not always easy to identify an influencer. Users normally understand that information is accurate when it comes from a reliable source, which does not necessarily mean an influencer. Therefore, if a message does not convey relevance and reliability to users, it will not be retweeted, regardless of who publishes it.

In the case of lexical diversity, we found support for the $\mathrm{H} 7$ hypothesis $(\beta=0.160, \mathrm{p}<0.000)$. Individuals with greater diversity often receive retweets. This happens because if the messages posted by an individual have variety in the topics covered, there will be some individual who finds it interesting for the community, so they tend to share it.

Finally, the $\mathrm{H} 8$ hypothesis was also supported $(\beta=0.100, p<0.000)$. This relates to the fact that Twitter creates strong links between users within the virtual community. When a user follows many people, he/she has a greater chance of visibility because his/her closest community is larger. Moreover, if that community perceives the user as a reliable source of information, they will tweet again information that may be of interest to the whole community, not only to users who follow each other.

In line with the results obtained, we can point out that communication on a microblogging platform such as Twitter, improves the diffusion with a specific writing style. The correct elaboration of a message means a greater capacity of diffusion (through a retweet). Therefore, we find a clear relationship between the elements included in a tweet and its probability of dissemination.

Following many users on Twitter also favours retweeting. Although it would seem more logical to use the number of followers an individual has, this metric has been left out of the study as it is part of the algorithm that measures the level of influence. Hence, this is a very interesting result because it implies that it is not enough to have many followers on Twitter to spread the message, but it also depends on the content and characteristics (heuristic cues) of the message. In fact, there are already studies that show that trust in the friends we have on a social network is a confidence-building factor that is the basis for future behavioural intent, such as sharing content through a retweet (Cordero-Gutiérrez, 2018).

Hashtags are a characteristic feature in tweets, as they are highlighted with the \# symbol and make the word appear in another colour. But we should be aware that additional hashtags can take space away from the tweets. Since Twitter allows searching without the \# symbol, they have lost some relevance in searches and we understand that this fact does not contribute to getting a retweet. On the contrary, mentions become an important

Table 1. Regression Results

\begin{tabular}{llcccc}
\hline Dependent variable & Independent variables & $\boldsymbol{\beta}$ & $\boldsymbol{\beta}$ standardized & p-value & Model fit \\
\hline \multirow{4}{*}{ Retweet } & Constant & -0.422 & & 0.000 & \\
& Mentions & 0.344 & 0.392 & 0.000 & R square $=0.269$ (Adjusted R square $=0.266$ ) \\
& Lexical diversity & 0.351 & 0.160 & 0.000 & 0.000 \\
& Tweet length & 0.012 & 0.136 & 0.000 & 0.000 \\
& Followings & 0.0007437 & 0.100 & 0.000 & \\
& Sentiment & 0.092 & 0.093 & & \\
\hline
\end{tabular}


element because they link users to each other within the virtual community. In the same line, links are not recommended because when an individual finds that the information in a message is reliable, he or she does not need to use additional external cues to validate it. In addition, some authors point out that users consider the links that appear in tweets to be "spammers" (Benevenuto et al., 2010), which discourages the dissemination of messages. The length of the tweet has become a controversial issue because there are studies that indicate that longer tweets are more important and interesting for users (Tao et al., 2012), but other studies also indicate the opposite (Sales Force, 2012).

Not only the length is important, but also the variety of vocabulary used (lexical diversity). When a tweet uses more varied and non-technical or specific words, they have a greater impact on the reader because he or she is able to understand the message with ease (heuristic cue), which increases retweets.

In addition, we observed through this study that users prefer messages that show a positive or negative feeling towards a product, service or brand. Neutrality goes unnoticed by users. Consumers tend to trust the opinions of their peers more than company references, as they are perceived as "honest and accurate" (Lahuerta-Otero \& Cordero-Gutiérrez, 2016).

\section{Conclusions}

\section{Academic Implications}

One of the main problems that companies face in microblogging networks is getting a space for the user's attention among the thousands and thousands of messages that are produced each minute. This type of platform, if anything, is characterized by its speed and immediacy. That is why one of the most important challenges is to stand out and make sure that the generated content reaches the users. This study offers complementary variables to understand how users write and behave in microblogging communities. We incorporated a new variable to the existing literature on retweeting: influence. This variable is a unique dimension based on Twitter activity and provides more specific information about the microblogging site compared to the Klout score. As the Klout score takes into account the social profiles of all users, it penalizes users who do not have an active account on all different social media sites. In contrast, the influence provides unique information about the community created around a Twitter user, being more specific and therefore more reliable.

Our model suggests that tweets can be more effective in terms of retweeting if they include a specific set of heuristic cues, as they facilitate information process- ing by allowing for greater dissemination. However, the regression model also shows that not all heuristic cues are relevant for retweeting, since users seem to be disturbed by some elements (hashtags and links) that were originally considered to facilitate dissemination. Therefore, users wishing to create an impact on their community should add appropriate tweeting elements (mentions, sentiment, lexical diversity, and tweeting characters) when posting. This study provides alternative criteria for measuring the number and effectiveness of heuristic cues on microblogging platforms, which is important for providing a joint picture of how users create conversations about brands.

\section{Managerial Implications}

This study allows us to make important recommendations about the policy of publishing a topic on Twitter. Thanks to the results obtained, companies or users with profiles on Twitter can have a greater impact on their publications. In the case of organizations, this can help them optimize their dissemination actions, reaching more audiences with less effort and in a more efficient way.

Standing out in the vast ocean of tweets is not easy, but paying attention to message content and heuristic cues can help users be seen over the rest. If the messages companies post on social networks increase their reach and engagement, it will help them improve their business relationships with customers, which are vital in an increasingly competitive market. If an individual becomes an ambassador for a brand, product, or service by talking about it on Twitter, it is the best communication a company can use since that e-WOM is perceived as non-commercial and reliable.

Individuals tend to trust more and more those users who are understood to be similar to them and not so much companies or brands. This fact makes the work of a good community manager who knows how to highlight a company's messages over the rest of the information in order to increase dissemination more important.

Therefore, if brands make proper use of Twitter features when publishing, they can increase the spread of messages. This dissemination of messages can be done equally by all types of users, regardless of their social influence. This is of great importance and a remarkable result of our research, because by changing only the way they publish, brands can favour from a greater social impact without additional cost. Based on the empirical results of our research, longer tweets containing sentiment, mentions, and lexical diversity get more retweets. Although hashtags and links seem to be important heuristic cues in the literature, our research shows that they reduce the number of characters, which means that users have less writing space available. In addition, links cause 
users to leave the Twitter page for another alternative, which prevents them from reading and processing the information. Therefore, these elements should be avoided within the main page to improve retweeting, but they can be added in the comments or in the biography section if necessary in order to improve online positioning.

\section{Limitations and Further Research}

We would also like to point out some limitations of this study. We used a single keyword (Nissan) collecting tweets in a period of only 12 days. The sample should be expanded to make the conclusions more robust. In addition, we can add new elements in the analysis that are part of the characteristics of the user who writes them or the structure or theme of the tweet itself. Alternatively, we can explore additional relationships between variables, such as comparative hypotheses. Finally, the data collection period can be extended to obtain richer data. These limitations will be addressed in future research.

\section{Acknowledgement}

This work was supported by the Ministry of Industry, Energy and Tourism (Strategic actions of economy and society, 2015). SOGESCLOUD - Máquina social auto-adaptativa para la gestión corporativa en la nube [grant number TSI-100104-2015-007].

\section{References}

Alexander, J. E., \& Tate, M. A. (1999). Web wisdom: How to evaluate and create information quality on the web. Lawrence Erlbanm Associates Publishers.

Augure. (2014). Informe Augure sobre el estatus del marketing the influencers. http://www.augure.com/es/ blog/influencer-marketing-estatus-20140220.

Bae, Y. \& Lee, H. (2012). Sentiment analysis of Twitter audiences: Measuring the positive or negative influence of popular twitterers. Journal of the American Society for Information Science and Technology, 63(12), 2521-2535.

Benevenuto, F., Magno, G., Rodrigues, T., \& Almeida, V. (2010). Detecting spammers on twitter. Paper presented at: Collaboration, electronic messaging, anti-abuse and spam conference (CEAS), 6, No. 12.

Bennet, S. (2014). The optimal length of a tweet, hashtag, podcast, slideshare and (almost) everything online. https://goo.gl/1QUGv1

Bongwon, S., Lichan, H., Peter, P., \& Chi, E.H. (2010). Want to be retweeted? Large scale analytics on factors impacting retweet in twitter network. Paper presented at: IEEE International Conference on Privacy, Security, Risk and Trust, 177-184.
Boyd, D., Golder, S., \& Lotan, G. (2010). Tweet, tweet, retweet: Conversational aspects of retweeting on twitter. Paper presented at: System Sciences (HICSS), 2010 43rd Hawaii International Conference (1-10). IEEE.

Brooke, J., Tofiloski, M., \& Taboada, M. (2009). Cross-linguistic sentiment analysis: From English to Spanish. In RANLP, 50-54.

Carr, G. \& Brock, T. (2013). Klout matters: How to engage customers, boost your digital influence-and raise your Klout score for success. McGraw Hill Professional.

Cha, M., Haddadi, H., Benevenuto, F. \& Gummadi, P.K. (2010). Measuring user influence in Twitter: The million follower fallacy. ICWSM 10, 10-17.

Chaiken, S. (1980). Heuristic versus systematic information processing and the use of source versus message cues in persuasion. Journal of Personality and Social Psychology, 39(5), 752-766.

Chaiken, S. (1987). The heuristic model of persuasion in social influence. In Mark P. Zanna et al. (Eds.), The Ontario symposium, 5, 3-39.

Chu, S.C. \& Kim, Y. (2011). Determinants of consumer engagement in electronic word-of-mouth (eWOM) in social networking sites. International Journal of Advertising, 30(1), 47-75.

Cordero-Gutiérrez, R. (2018). Redes sociales horizontales y su impacto en el ámbito empresarial y social (Doctoral dissertation, Thesis doctoral). Universidad de Salamanca.

Enge, E. (2014). Twitter engagement unmasked: A study of more than $4 \mathrm{M}$ tweets. https://goo.gl/ao6Jj0

Erkan, I. \& Evans, C. (2016). The influence of eWOM in social media on consumers' purchase intentions: An extended approach to information adoption. Computers in Human Behaviour, 61, 47-55.

Flanagin, A. J., \& Metzger, M. J. (2007). The role of site features, user attributes, and information verification behaviours on the perceived credibility of web-based information. New Media and Society, 9(2), 319-342.

Fogg, B.J. (2003). Prominence-interpretation theory: explaining how people assess credibility online, $\mathrm{CHI} 03$ Extended Abstracts on Human Factors in Computing Systems, April 05-10, 2003, Ft. Lauderdale, Florida, USA[doi: 10.1145/765891.765951].

Gul, S., Mahajan, I., Tun Nisa, N., Ahmad Shah, T., Jan, A., \& Ahmad, S., (2016). Tweets speak louder than leaders and masses: An analysis of tweets about the Jammu and Kashmir elections 2014. Online Information Review, 40(7), 900-912.

Hansen, L.K., Arvidsson, A., Nielsen, F.A., Colleoni, E., \& Etter, M. (2011). Good friends, bad news - Affect and virality in twitter. In Future information technology, 34-43. 
Hao, X, Zheng, D., Zeng, Q., \& Fan, W. (2016). How to strengthen the social media interactivity of e-government: Evidence from China. Online Information Review, 40(1), 79-96.

Hoeber, O., Hoeber, L., El Meseery, M., Odoh, K., \& Gopi, R. (2016). Visual Twitter analytics (vista): Temporally changing sentiment and the discovery of emergent themes within sport event tweets. Online Information Review, 40(1), 25-41.

Hutchison, K., \& Kumara, S. (2013). Big data analytics-sentiment analysis of Twitter data using clustering techniques. Paper presented at: IIE Annual Conference. Proceedings (p. 2495). Institute of Industrial Engineers-Publisher.

Ikeda, K., HattoriI, G., Ono, C., Asoh, H., \& Higashino, T. (2013). Twitter user profiling based on text and community mining for market analysis. Knowledge-Based Systems, 51, 35-47.

Infographic list (2012). Does more influence equal more retweets [infographic]. http://infographiclist. com/2012/02/16/does-more-influence-equal-moreretweets-infographic-2/

Internet Live Stats. (2020). https://goo.gl/3F7btG

Jansen, B.J., Zhang, M., Sobel, K., \& Chowdury, A. (2009). Twitter power: Tweets as electronic word of mouth. Journal of the American Society for Information Science and Technology, 60(9), 1-20.

Java, A., Song, X., Finin, T., \& Tseng, B. (2007). Why we Twitter: Understanding microblogging usage and communities. In Zhang, H., Mobasher, B., Giles, C.L., McCallum, A., Nasraoui, O., Spiliopoulou, M., Srivastava, J. \& Yen, J. (Eds), Proceedings of the Ninth WebKDD and First SNA-KDD 2007 Workshop on Web Mining and Social Network Analysis (pp. 56-65). ACM.

Kietzmann, J. H., Hermkens, K., McCarthy, I. P., \& Silvestre, B. S. (2011). Social media? Get serious! Understanding the functional building blocks of social media. Business Horizons, 54(3), 241-251.

Klout. (2016). The Klout score. https://klout.com/corp/ score

Lahuerta-Otero, E., \& Cordero-Gutiérrez, R. (2016). Looking for the perfect tweet. The use of data mining techniques to find influencers on twitter. Computers in Human Behaviour, 64, 575-583.

Lahuerta-Otero, E., Cordero-Gutiérrez, R., \& De la Prieta-Pintado, F. (2018). Retweet or like? That is the question. Online Information Review, 42(5), 562-578.

Lang, A. (2000). The limited capacity model of mediated message processing. Journal of Communication, 50(1), 46-70.
Lee, K. (2015). What analysing 1 million tweets taught us. http://tnw.to/s3R2i.

Liu, Z., Liu, L. \& Li, H. (2012). Determinants of information retweeting in microblogging. Internet Research, 22(4), 443-466.

Malhotra, A., Malhotra, C.K. \& See, A. (2012). How to get your messages retweeted. MIT Sloan Management Review, 53(2), 61-66.

Direct Marketing (2020). Los políticos latinoamericanos son los que mejor usan las redes sociales. https://www.marketingdirecto.com/digital-general/ social-media-marketing/los-politicos-latinoamericanos-son-los-que-mejor-usan-las-redes-sociales

Mavrck (2014). How a reply, favourite, or retweet reflects influence. http://www.mavrck.co/how-a-reply-favorite-or-retweet-reflects-influence/

Messias, J., Schmidt, L., Oliveira, R., \& Benevenuto, F. (2013). You followed my bot! Transforming robots into influential users in Twitter. First Monday, 18(7), 1-14.

Metzger, M. J., Flanagin, A. J., \& Medders, R. B. (2010). Social and heuristic approaches to credibility evaluation online. Journal of Communication, 60(3), 413-439.

Nissan. (2018). Nissan posts record sales and market share in Latin America in FY2017. https://global.nissannews.com/ja-JP/releases/release-36a71146ed04eaba0f0dff94b5139c58-nissan-posts-record-sales-andmarket-share-in-latin-america-in-fy2017? source=nng

Oh, H. \& Nguyen, C. (2010). Influence of retweets. http:// snap.stanford.edu/class/cs224w-2010/proj2010/35 Final\%20Paper.pdf

Okazaki, S., Díaz-Martín, A. M., Rozan-Suplet, M., \& Menéndez-Benito, H.D. (2014). Explotando datos de Twitter: cómo captar las relaciones entre clientes. In Experiencia y comportamiento del cliente en un entorno multicanal: claves de éxito para fabricantes y detallistas (pp. 379-397). Ed. Cátedra Fundación Areces de Distribución Comercial.

Parker, M. B., Moleshe, V., De la Harpe, R., \& Wills, G. B. (2006). An evaluation of information quality frameworks for the world wide web. Paper presented at: The 8th Annual Conference on WWW Applications, Bloemfontein, September 6-8.

Reynolds, G. (2006). An army of Davids: How markets and technology empower ordinary people to beat big media, big government, and other Goliaths. Thomas Nelson.

Ross, P. (2014). Photos get the most engagement on Twitter. https://goo.gl/6rVFv4

Russell, M. A. (2013). Mining the social web: Data mining Facebook, Twitter, LinkedIn, Google, GitHub, and more. O’Reilly Media, Inc. 
Sales Force. (2012). Strategies for effective Tweeting: A statistical review. http://www.salesforcemarketingcloud.com/wp-content/uploads/2013/03/Strategies-for-effective-tweeting.pdf

Sankaranarayanan, J., Samet, H., Teitler, B. E., Lieberman, M. D., \& Sperling, J. (2009). TwitterStand: News in tweets. Paper presented at: GIS '09: Proceedings of the 17th ACM SIGSPATIAL international conference on advances in geographic information systems, 42-45.

Scott, K. (2015). The pragmatics of hashtags: Inference and conversational style on Twitter. Journal of Pragmatics, 81, 8-20.

Statista (2020a). Number of monthly active Twitter users. https://www.statista.com/statistics/282087/number-of-monthly-active-twitter-users/

Statista. (2020b). Number of Twitter users in Latin American countries. https://www.statista.com/statistics/977791/number-twitter-users-in-latin-american-countries/

Steyn, P., Ewing, M. T., van Heerden, G., Pitt, L. F., \& Windisch, L. (2011). From whence it came: Understanding source effects in consumer generated advertising. International Journal of Advertising, 30(1), 133-160.

Strong, D. M., Lee, Y. W., \& Wang, R. Y. (1997). Data quality in context. Communications of the ACM, 40(5), 103-110.

Syrkiewitcz-Switala, M., Lar, K., \& Holecki, T. (2016). The use of social media and social media marketing tools by the polish marshal offices to promote health. China-USA Business Review, 15(7), 330-336.

Tao, K., Abel, F., Hauff, C., \& Houben, G. J. (2012). What makes a tweet relevant for a topic. Making Sense of Microposts, 49-56 (\#MSM2012).

Taraborelli, D. (2008). How the Web is changing the way we trust. In K. Waelbers, A. Briggle, \& P. Brey (Eds.). Current issues in computing and philosophy. IOS Press.
Twitter (2016). Coming soon: Express even more in 140 characters. https://goo.gl/7jj3AS

Urban, G. (2005). Don't just relate advocate: A blue print for profit in the era of customer power. Wharton School Publishing.

Wang, R., Liu, W., \& Gao, S. (2016). Hashtags and information virality in networked social movement: Examining hashtag co-occurrence patterns. Online Information Review, 40(7), 850-866.

Ward. (2019). Inside the discovery mindset on Twitter And what it means for brands. https://marketing.twitter.com/na/en/insights/inside-the-discovery-mindseton-twitter-and-what-it-means-for-brands

We Are Social \& Hootsuite (2020). Digital in 2020 global overview. https://wearesocial.com/digital-2020

Weng, J., Lim, E. P., Jiang, J., \& He, Q. (2010). Twitterrank: Finding topic sensitive influential twitterers (pp. 261-270). Paper presented at: Proceedings of the third ACM international conference on Web search and data mining, ACM.

Zhang, L., Peng, T. Q., Zhang, Y. P., Wang, X. H., \& Zhu, J. J. (2014). Content or context: Which matters more in information processing on microblogging sites. Computers in Human Behaviour, 31, 242-249.

Zhang, L., \& Peng, T. Q. (2015). Breadth, depth, and speed: Diffusion of advertising messages on microblogging sites. Internet Research, 25(3), 453-470.

Zhang, W., \& Watts, S. A. (2008). Capitalizing on content: Information adoption in two online communities. Journal of the Association for Information Systems, 9(2), 73-95. 